\title{
Effect of wisdom and intellectuality on social health
}

Alireza Atarodi Beimorghi ${ }^{1}$, Nadjla Hariri ${ }^{1}$, Fahimeh Babalhavaeji ${ }^{1}$

\author{
Journal of Research \& Health \\ Social Development \& Health Promotion \\ Research Center \\ Vol. 7, No. 1, Jan \& Feb 2017 \\ Pages: 624- 636. \\ DOI: 10.18869/acadpub.jrh.7.1.624 \\ Original Article
}

1. Department of Knowledge and Information Science, Science and Research Branch, Islamic Azad University, Tehran, Iran

Correspondence to: Nadjla Hariri, Department of Knowledge and Information Science, Science and Research Branch, Islamic Azad University, Tehran, Iran

Email: nadjlahariri@gmail.com

Received: 1 Jun 2016

Accepted: 14 Sep 2016

How to cite this article: Atarodi Beimorghi A, Hariri N, Babalhavaeji F. Effect of wisdom and intellectuality on social health. $J$ Research \& Health2017; 7(1): 624- 636.

\begin{abstract}
Human social life and social health is significant. Wisdom and intellectuality can affect individual and social life of the human and help to form his social life. The aim of this study was to investigate effect of wisdom and intellectuality on a healthy social life. This is a qualitative study with Grounded theory approach. The participants were 59 individuals online on the web who were selected through theoretical sampling in purposeful method. The data were collected by a semi-structured interview through an online interview using Q \& A Yahoo! Answers software (yahoo answers). The interviews were analyzed and necessary concepts were extracted from the literature by Straus and Corbin Model. Most of the participants in the study mentioned the sub-categories of social life dimensions such as having knowledge, experience, understanding, and insight (37.73\%). Some other concepts were also emphasized such as the use of knowledge with $6.6 \%$ and making a right decision at the right time as effective on life with $5.66 \%$. From 88 concepts, 7 sub-categories and 6 main categories were formed. The wise man is humble, teachable, and willing to learn. He is not conceited and arrogant but, he is sage. The wise man brings the knowledge into practice and uses it in the context of his life and society to experience a life with deep understanding through wisdom and intellectuality; this can, in turn, create a life with the sense of satisfaction and form a social healthy life, as well.
\end{abstract}

Keywords: Information, Intellectual, Knowledge, Social Health, Wisdom

\section{Introduction}

Human being needs health to survive and his health depends on many factors. Now, this question shapes in mind that is there a proper way, less costly, and more comprehensive to achieve a wise, healthy social life? It seems that one of the factors which, if used truly and put knowledge in its right place accompanied with morality for positive influence, may have productive effects on physical, mental, and particularly social health of any person and the society.

A wise man in his social and individual behaviors selects the best behaviors. Successful life and social wellbeing of individuals is emerged from rationality of members, and in this way, it will ensure the community health. Wisdom and being wise as well as intellectual life cause cheerful social spirit and make an intellectual, positive interaction that brings for community mental 
health with a sense of satisfaction with life.

In other words, health is an issue that is important in any general discussion especially in related academic areas and has engaged the minds of many specialists. Today, health is not defined only in relation to physical illness or infectious diseases. Health is involving in any field affected physical, psychosocial, and social health directly or indirectly. Human being with the power of thought and wisdom and with the help of knowledge, rationality and experience, or in other words, with the help of reason and wisdom and pure thoughts has been able to overcome their problems and illnesses and he could pave their way to health [1]. As the man is not happy in the world without eyes and without health, he will be unable to benefit from life without wisdom; when joy and happiness is lost, he will be exhausted and ailments will overcome him [2]. Secretary General of the Iranian National Commission for UNESCO has stated that scientific progress today has transformed our life, but advances in science has not necessarily made our life better in peace. The purpose of technology is to reduce human pain, but science without morals and wisdom is not clear to lead us to final destination [3]. It seems that in our time, the ignorance of history and identity has strongly suspended our generation and human morality and social cohesion is under threat and being forgotten; damages caused by the catastrophic issue has weakened the community psychological conditions every day, then, it seems a throwback to intellectuality culture is a crucial necessity [4].

Wisdom is accumulated knowledge and experience in the learning organization; it is judgment between good and evil and the ability to solve problems and to create value. Wisdom answers "why?" it selects which knowledge should be used to achieve each goal. Wisdom understands the principles of reason and can provide social health for human society [5].

"Samuel Smiles", the English author, says the man can overcome all difficulties and hardships and he can reach all things focused in his mind, provided that he uses unwavering endurance and positive attitude and wisdom toward his own way; a wise man in his individual, social behavior chooses the best lifestyle. Talents and innovation' inflorescence in human life needs wisdom [6-7]. So, it is a necessity for wise men in Muslim community to try to cultivate the tree of wisdom and rationality on this land and through this, all human features under the shadow of wisdom and rationality in an ideal state are emerged to ensure his health [8]. So, thinking in a rational way is an inevitable issue that any society needs it [9]. Intellectuality and wisdom is of God wonders and a sign for those who understand wisdom and have any familiarity with it [10]. Elsewhere he speaks of those who have turned their life into a hell of sorrow saying: "If used properly the gift of wisdom, we would not have such a hell of pain and sorrow" [11]. So, being far from wisdom and intellectuality has bothered him and his community and disclaims health allround. According to Johnson, the eighteenthcentury English poet and lexicographer, the man who is philosophically wise, is needless of anything, because he has achieved perfection [12]. Social health of human will be improved and grown by reason and wisdom. The results of some studies suggest that wisdom is closely, directly related to health; especially in men, it is significantly related to health; it has also strong positive impact on human health and satisfaction with life [13]. The wise man is humble, teachable, and willing to learn; he is not conceited and arrogant; he is clairvoyant and questioner; he knows and accepts that what he knows against what he does not know is too little; and he has a common sense [14]. We have to believe that these individual and social evils throughout the world are originated from the lack of reason and wisdom because wisdom in life is as a limiter for his owner and does not allow him to exceed much in wrong way [15]. Modern man does not suffer from lack of knowledge, what caused him suffering and what has challenged his life is the lack of intellectual practical use of accumulated knowledge that can be one of the alternatives 
of reason and wisdom. Therefore, such studies suggest a large gap in modern societies between the current situation and the desired situation that has put social health in danger. It needs to be repaired and mended with scholars reflects, tactics, and wised diplomacy; it seems that getting knowledge and wisdom can be helpful in this direction. The prevention and vaccination of human life, faced with a flood of difficulties, to reach a healthy social life, effective antidotes such as knowledge and wisdom are needed more than ever. However, the social health has different definitions in different cultures and a definitive idea is undeclared about it; and social health is of the concepts that a precise definition is difficult for it. Diversity definitions in this area have caused different views that its right or wrong cannot be clearly identified. There is no formal definition of social health in the current literature [16].

In this study, however, we considered social health sub-components leading the society to wisdom and intellectuality. Keyes generally has noted social health in 5 dimensions (social cohesion, social acceptance, social adaptation, social participation, and social actualization) that are essential to a healthy social life [17]. Sub-components we reviewed in this study can shape the Keyes 5 dimensions of social health and they include its sub-structures; they are to shape social health from this perspective. Considering the significance of healthy life based on wisdom for the human society, we decided to conduct a research with the aim of determining the effect of wisdom and being wise on social health, a component which needs sub-components such as morals, social interaction, confidence, social competence, social participation, social tolerance, happiness, life satisfaction, modesty, humility and insight, with the appearance of wisdom and rationalism.

\section{Method}

This study is a qualitative research using Grounded Theory conducted in 4 stages on several samples. In fact, this qualitative study using grounded theory seeks to answer its questions through descriptions, decoding, interpretation, translation and understanding of concepts and meanings of phenomena of social environment and interpretation of the data. In other words, the study starts up in a field to emerge out the given answers based on data. To gather the data, we needed some samples that were selected according to theoretical sampling which is a variation of purposive sampling method. Since the sample size in this type of research is not pre-determined, the interviews and data collection were continued until the stage of saturation. The saturation was achieved when there were no new data and contents and the gathered data were distinguished as repeated. Since, in this research approach, preliminary data could be obtained from other techniques such as interviews, observation, documents and texts examination, we primarily searched on the books, articles, library sources, and the internet to find the required data and concepts. In the first stage of data gathering, the results of the books and other articles that were available in the same field were used and the content was extracted from the sources to be surveyed, used and discussed. In the second stage, a group of artists and actors in the majors of art and cinema and authors who were going to do a two-day fun program in Gonabad city were interviewed after getting permission from their respected agent when they were in the rest room. They were interviewed about wisdom and intellectuality, its impact on lifestyle and a healthy living, and how to reach it. Unfortunately, majority of the participants apologized and refused to do interview after being informed of the subject because of, according to their claim, its hardness and its depth; they stated that they do not see themselves able in this level. Only one of them completely passed the interview and one did a little. Thus, the researchers decided to miss the data in the second stage because of the inadequacy of the information for analysis and its negative impact on the research. In the third stage, a questionnaire was designed for interview including demographic information and 13 open-ended, descriptive questions on 
wisdom and intellectuality and its impact on individual and social health. It also included another open, free question at the end of the questionnaire for expressing a certain opinion (if needed). The questionnaire was carried out on Persian Word software to let the participants full answer the questions regardless of the space while they were asked not to hesitate detailed responses to the questions. After preparing the questionnaire, they were sent through Email to a group of faculty members of Gonabad University of medical sciences who had more experiences (over 10 years) at the university. After a while, only one completed questionnaire returned. Hence, we sent a reminder email to the same participants and asked them, despite their business and difficulties, complete the questionnaire if possible and return them back. But, unfortunately, after about 10 days, no questionnaire returned back which could be due to many reasons. Therefore, we disregarded this method of data gathering and used online interview for gathering data in the fourth stage. In addition, the only one returned questionnaire from faculty members was not analyzed and eliminated from the study. In the 4th stage, using Yahoo Answers application, a question as "What is wisdom and its impact on a healthy social life?" was introduced to the online users of Yahoo to respond. The method of this software is in a way that you put a question in the search box and then submit it in Yahoo search engine to send it to the users. This tool was designed in 2005 as previously worked in the form of ASK QUESTION (Yahoo! Q \& A). In this tool, people can ask questions and receive its response from others or they can answer questions asked by others reciprocally. The response time for users is 5 days and after 5 days no responses will be received, unless you ask a new question. We saved the responses every day and after transcription, translation and interpretation of the text, the answers to the questions were extracted and tabulated. At the end of 5 days and full receiving of the answers, once again we reviewed, interpreted and analyzed the received texts. Based on Strauss and Corbin [18], the data were compared to the original table to reform it until the table was completed. Finally, the related categories of the above texts on the definition of wisdom and its impact on social health were identified. In this method for the analysis of data, a threestep method of constant comparison of coding and analysis of data was used: a. Open coding, (discussing, comparing, conceptualizing and categorizing data), b. Axial coding (reaccumulation of data in groupings based on relationships and patterns within and among the identified categories in the data), and c. Selective coding (identification and description of major phenomena or categories or classes of the data), as mentioned in the model of Strauss and Corbin. In addition, Strauss and Corbin suggested that the selective coding and theory development for all researches performed in this way is not possible or may not be necessary and the research can be ended in the stage of conceptualizing and or in analyzing the concepts [18]. The participants replied little to the next question about the wisdom that was harder to understand and needed deeper thinking. The question was: "How knowledge can be transformed into wisdom?" Only 6 participants in two days answered the latter question that all were considered in analyzing as well. The interviews were conducted with participants' full satisfaction, informed consent, and permission and the confidentiality of their information was announced to them.

\section{Results}

To achieve a healthy community and satisfying life in the society, some components are required and these components can work better and make deeper impact when they are based on the result of human knowledge and wisdom, and only when wise men are at the head of the affairs in the society, those who can upgrade their knowledge to a higher level that this process should also be carried out in a determined process. For this purpose, two typical of the knowledge intellectual pyramid here are presented.

Knowledge pyramid (Figure 1): According 
to the current definitions, concepts and results, the pyramid of knowledge can be drawn as the following. Data are at the lowest level of the pyramid and wisdom is at the highest. There are some differences in the details but in general, there is a consensus about the movement and overall composition of the pyramid [19-20]. Another form of the pyramid of knowledge was drawn (Figure 2) that shows how wisdom is formed [21].

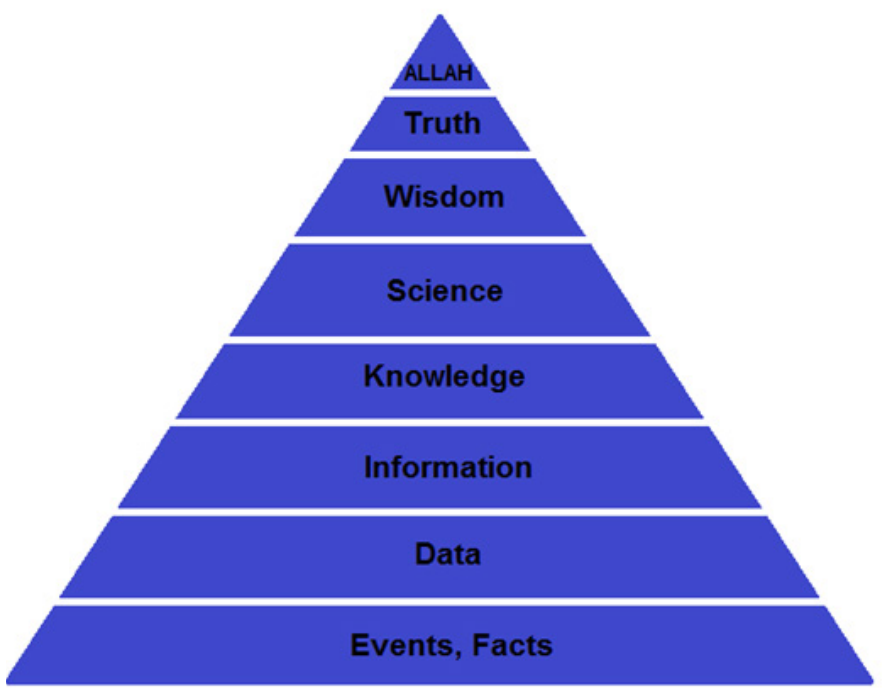

Figure 1 Pyramid of Knowledge (transforming knowledge into wisdom)

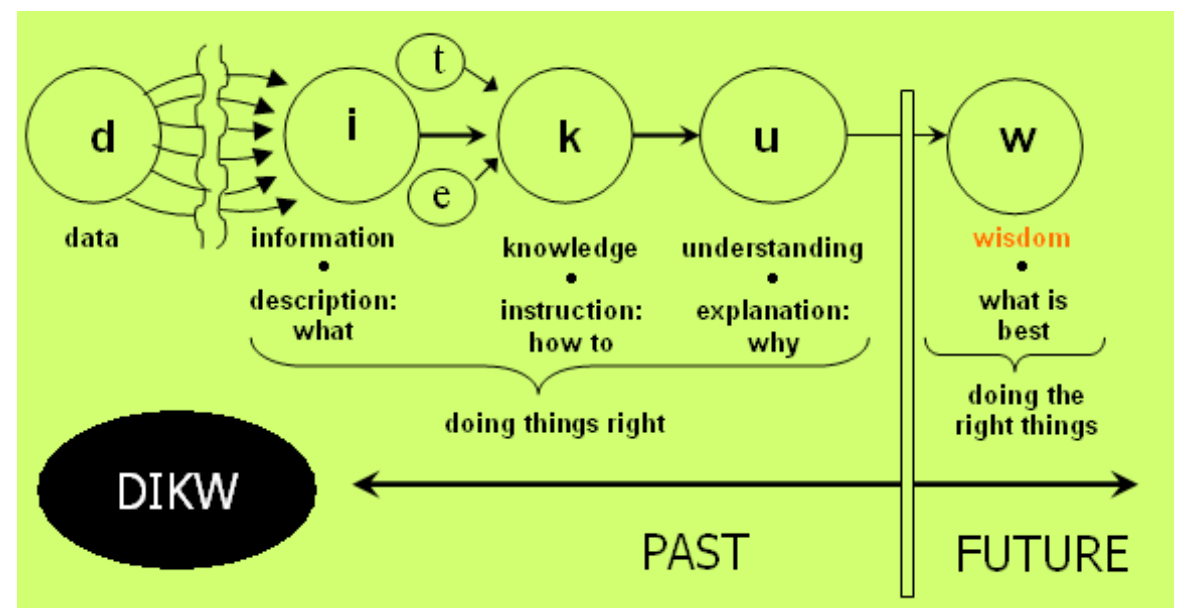

Figure 2 Pyramid of Knowledge [21]

Wisdom is shaped on the basis of knowledge and knowledge itself is based on data and information. In this way, data arises from the fact; and wisdom is the highest stage before the reality, i.e. the stage that is the aim of most researches. Since wisdom and intellectuality and its impact on social health is an abstraction issue and to some extent far from our minds, and requires strong, solid evidences from those who we call experts and elites, in the first stage, we referred to current texts to extract required data.

Therefore, the analysis of data obtained from the first stage, i.e. search in literature and current evidence, gave some results that its abstract in view point of intellectuals and experts and elite individuals such as Prophet Mohammad (PBUH) is as follows: A wise and rational man shows tolerance against an ignorant behavior towards himself, show 
patience, generous, humble, good-loving, benevolent, and behave well, avoids saying bad words, he fears of God, he is convincing, with modesty and not greedy. These are 10 features that the wise men are known by them [22-27] and each of these features can be the source of individual and social health. 10 features gained from the speeches and texts attributed to Imam Reza (AS) about wisdom and wise men that were found in the primary data gathering and indicate individual's mental and physical health, are as the following. In the view point of Imam Reza (AS), a wise man is someone who hope to goodness (and the poor in the society has not lost hope on him), people are relieved of his evil (and no one is afraid of him), a little goodness of other is valued much for him but, much goodness of him seems less to him, he is not bored of others begging for something, he is not tired of seeking knowledge during the life, he prefers to be poor in the way of God rather than be opulence, he prefers to be wretch in the sight of God rather than be great in the sight of enemy of God, anonymity for him is more interesting than popularity, and he considers all people better and more pious than himself [28]. From the 2nd and 3rd stages of the data collection in which the samples were faculty members and a group of artists and actors, no questionnaire returned back or not any deep interviews were gained, except two cases that were not considered due to the lack of sufficient information for the analysis. Then, no data or information is presented here. In the 4th stage of the work, some people participated in an online interview through FAQ Yahoo answers software that the initial coding was done for them as the following. (In fact, the main part of the work was analyzing the data from the online interview texts of the 4th stage of the collecting data by using Yahoo Answers software).

Table 1 Frequency distribution of necessary sub-components (concepts) for a wise healthy social life (open code) from the participants views

\begin{tabular}{|c|c|c|c|c|c|c|c|c|}
\hline Sub-components & $\mathrm{n}$ & $(\%)$ & Sub-components & $\mathrm{n}$ & $(\%)$ & Sub-components & $\mathrm{n}$ & $(\%)$ \\
\hline Having knowledge & 10 & 9.43 & $\begin{array}{l}\text { Ability of deep } \\
\text { understanding }\end{array}$ & 10 & 9.43 & $\begin{array}{l}\text { Ability of } \\
\text { achieving } \\
\text { experience }\end{array}$ & 10 & 9.43 \\
\hline $\begin{array}{l}\text { Ability of insight(to } \\
\text { know good from } \\
\text { evil) }\end{array}$ & 10 & 9.43 & $\begin{array}{l}\text { Ability of putting } \\
\text { knowledge into } \\
\text { practice }\end{array}$ & 7 & 6.6 & $\begin{array}{l}\text { Ability of self- } \\
\text { knowing }\end{array}$ & 6 & 5.66 \\
\hline $\begin{array}{l}\text { Power of decision } \\
\text { making }\end{array}$ & 6 & 5.66 & Impact on life & 6 & 5.66 & Fear of God & 4 & 3.77 \\
\hline $\begin{array}{l}\text { Having knowledge } \\
\text { and experience }\end{array}$ & 4 & 3.77 & Seeks of reality & 3 & 2.83 & $\begin{array}{l}\text { Having good } \\
\text { thought }\end{array}$ & 3 & 2.83 \\
\hline Having morality & 3 & 2.83 & Situation knowing & 3 & 2.83 & $\begin{array}{c}\text { Have } \\
\text { humility }\end{array}$ & 3 & 2.83 \\
\hline $\begin{array}{l}\text { Try to improve } \\
\text { knowledge in higher } \\
\text { level }\end{array}$ & 2 & 1.89 & $\begin{array}{l}\text { Having inherent } \\
\text { positive } \\
\text { characteristics }\end{array}$ & 2 & 1.89 & $\begin{array}{l}\text { Ability to tolerate } \\
\text { pain and sorrow }\end{array}$ & 2 & 1.89 \\
\hline $\begin{array}{l}\text { To have higher } \\
\text { power }\end{array}$ & 2 & 1.89 & $\begin{array}{l}\text { To have tolerance } \\
\text { and patience }\end{array}$ & 1 & 0.94 & $\begin{array}{l}\text { Having common } \\
\text { sense }\end{array}$ & 1 & 0.94 \\
\hline $\begin{array}{l}\text { Ability to control } \\
\text { emotions }\end{array}$ & 1 & 0.94 & $\begin{array}{c}\text { To express love \& } \\
\text { kindness }\end{array}$ & 1 & 0.94 & $\begin{array}{c}\text { Be truthful \& } \\
\text { saying right }\end{array}$ & 1 & 0.94 \\
\hline Being relax & 1 & 0.94 & $\begin{array}{l}\text { Improving } \\
\text { himself to wisely } \\
\text { understanding }\end{array}$ & 1 & 0.94 & $\begin{array}{c}\text { Ability of } \\
\text { participation }\end{array}$ & & 0.94 \\
\hline $\begin{array}{l}\text { Having positive } \\
\text { human properties }\end{array}$ & 1 & 0.94 & Be logic \& rational & 1 & 0.94 & Sum & 31 & 29.24 \\
\hline Sum & 40 & 37.74 & Sum & 35 & 33.02 & Total & 106 & 100 \\
\hline
\end{tabular}


The Open Coding: In this stage, all the key points and phrases of interview texts were extracted and labeled a concept or code which called sub-components. These sub-components helped us to form social health dimensions for setting up a wisely health social life. They are listed in the Table 1.

Table 1 shows that 59 participants from different countries of the world participated in a 5-day online interview that the volume of comments they had written and submitted differed from a line to one page. Upon the receipt, we started reviewing and studying the received texts and transcription, and also extracting, analyzing and coding the texts. A total of 106 concepts (sub-components) were extracted using open and axial coding on the necessary components regarding wisely and healthy social life from the comments of the participants which were summarized in Table 1. To extract the concepts, the opinions of two other experts (peer reviewer) were also used. The participants had different ideas and examples of the components in their mind and belief. The most frequent concepts described in Table 1 indicated that a wise man must: 1) have knowledge, 2) Experience, 3) the ability of deep understanding, and 4) The power of insight (power of distinction between good and evil). Each concept showed equal frequency of $9.43 \%$ that these four concepts or codes comprised in total $37.73 \%$ of the concepts extracted from the text interviews of the participants.

Table 2 Example of concepts, categories, and social health dimensionsand main categories (classes) based on data

\begin{tabular}{|c|c|c|c|c|}
\hline Freq. & Concepts and open codes & Categories(sub-classes) & $\begin{array}{l}\text { Related social health } \\
\text { dimensions }\end{array}$ & Main categories (classes) \\
\hline 10 & $\begin{array}{l}\text { Having knowledge and be } \\
\text { aware }\end{array}$ & \multirow{2}{*}{$\begin{array}{l}\text { Achieving living } \\
\text { necessary knowledge \& } \\
\text { experience by human }\end{array}$} & \multirow[b]{2}{*}{ Social acceptance } & \multirow{4}{*}{$\begin{array}{l}\text { Creating a dynamic educational } \\
\text { and research environment and } \\
\text { rational and proper management } \\
\text { and use of knowledge in practice } \\
\text { and experience together to have a } \\
\text { wise \& healthy life }\end{array}$} \\
\hline 10 & $\begin{array}{l}\text { Achieving and applying } \\
\text { experience in life }\end{array}$ & & & \\
\hline 10 & $\begin{array}{l}\text { Deep understanding of the } \\
\text { issues }\end{array}$ & \multirow{2}{*}{$\begin{array}{l}\text { Getting deep insight \& } \\
\text { true understanding of the } \\
\text { affairs \& judgment }\end{array}$} & \multirow{2}{*}{$\begin{array}{l}\text { Social adaptation \& } \\
\text { self-actualization }\end{array}$} & \\
\hline 10 & $\begin{array}{l}\text { Having insight (distinguish } \\
\text { good from evil) }\end{array}$ & & & \\
\hline 7 & $\begin{array}{l}\text { Using knowledge \& } \\
\text { putting it into practice }\end{array}$ & \multirow{2}{*}{$\begin{array}{l}\text { To apply knowledge } \\
\text { and use knowledge and } \\
\text { experiences of others }\end{array}$} & \multirow{2}{*}{ Social acceptance } & \multirow{2}{*}{$\begin{array}{l}\text { Practical training based on local } \\
\text { experiences related to creating } \\
\text { and building a dynamic, logical } \\
\text { and social exhilaration }\end{array}$} \\
\hline 4 & $\begin{array}{l}\text { Having knowledge \& } \\
\text { experience together }\end{array}$ & & & \\
\hline 6 & $\begin{array}{l}\text { Make the right decision at } \\
\text { the right and proper time }\end{array}$ & \multirow{2}{*}{$\begin{array}{c}\text { Decision-making properly } \\
\text { based on knowledge and } \\
\text { time }\end{array}$} & \multirow{2}{*}{$\begin{array}{l}\text { Social adaptation \& } \\
\text { social participation }\end{array}$} & \multirow{2}{*}{$\begin{array}{l}\text { Enabling continuous education } \\
\text { to make the right decision at the } \\
\text { right time for social interaction } \\
\text { and public participation }\end{array}$} \\
\hline 6 & $\begin{array}{l}\text { Knowing and } \\
\text { understanding correct \& } \\
\text { right conditions }\end{array}$ & & & \\
\hline 6 & $\begin{array}{l}\text { Self-Knowing and } \\
\text { understanding himself in life }\end{array}$ & \multirow{3}{*}{$\begin{array}{l}\text { Self-Knowing and proper } \\
\text { understanding of him in } \\
\text { his life and discovering } \\
\text { the truth }\end{array}$} & \multirow{3}{*}{ Social acceptance } & \multirow{3}{*}{$\begin{array}{l}\text { Education based on self-knowing } \\
\text { and understanding of life for a } \\
\text { happy and healthy social life }\end{array}$} \\
\hline 3 & $\begin{array}{l}\text { To reach to the stage of } \\
\text { scientific humility }\end{array}$ & & & \\
\hline 3 & $\begin{array}{l}\text { Exploring and } \\
\text { understanding the truth or } \\
\text { achieve it }\end{array}$ & & & \\
\hline 4 & Fear of God & \multirow{2}{*}{$\begin{array}{l}\text { To reach to morality and } \\
\text { fear of God }\end{array}$} & \multirow{2}{*}{ Social adaptation } & \multirow{2}{*}{$\begin{array}{l}\text { The necessity consideration } \\
\text { of moral-ethical \& faith-based } \\
\text { social \& constructive education }\end{array}$} \\
\hline 3 & Having morality and ethics & & & \\
\hline 6 & $\begin{array}{l}\text { Positive influence on daily } \\
\text { life }\end{array}$ & $\begin{array}{l}\text { Positive impact of } \\
\text { wisdom on a healthy } \\
\text { social life }\end{array}$ & Social actualization & $\begin{array}{l}\text { Enabling people to understand } \\
\text { and use wisdom and } \\
\text { understanding its impact to } \\
\text { human flourishing and emerging } \\
\text { of a social healthy lifestyle }\end{array}$ \\
\hline
\end{tabular}


Secondary coding or forming categories based on concepts (initial coding): In this phase, initial codes resulted from open coding or subcomponents were transformed into conceptual categories (sub-classes), and main classes recorded in the below table. They were mixed and merged together in an upper class which was more abstract than before to form social health dimensions as Keyes has referred to. These dimensions in turn need special infrastructure and conditions that have been pointed out in main classes or main categories. Table 2 shows that on the basis of conceptual codes (sub-components) and presented categories, 6 main categories consisted of 88 basic concepts (sub-components) were formed. The relation of sub-components and categories to social health dimensions are shown in Table 2. As has been mentioned in the categories of the table, we need effective, dynamic educational backgrounds based on knowledge and native experiences and we should empower wisdom and wise men in the interaction with the surrounding environment to have a healthy society and social health. The ways and needed strategies for reaching the desires and emerging these sub-components and categories have also been expressed. To achieve social cohesion that is the first social health dimension in Keyes point of view, some sub-components and capabilities seem necessary such as interaction of individuals with the community and with each other; knowledge and insight could also be helpful to make a stronger social cohesion. To achieve social acceptance which is the second dimension of social health, other sub-components and capabilities such as love, compassion, cooperation, confidence and kindness seem necessary. The people in a community can achieve them through knowledge and wisdom, experiencing, and constant practice of the mentioned subcomponents. In order to achieve the third dimension of social health that is social adaptation, the dimension that also has been called human mastery over the environment, we need the components and concepts originated from wisdom and intellectual culture like having a logical view, deep understanding and insight and a sense of rational truth-seeking that has been tabulated in Table 1. In Keyes point of view, social participation is the fourth dimension of social health. Social participation is formed when someone believes he is a part of the community and he has positive impact on oneself and others life [29]. He accounts himself for the human world and humanity and he knows that he has human characteristics, therefore he loves others and is loved by others. Social participation also is composed of some infrastructures and sub-components such as having human characteristics, being effective in his life and others' life, being able to express love and affection, having a sense of cooperativeness, and having the power of patience and tolerance that are listed in Table 1. The fifth dimension of social health is social flourishing or self-actualization and this is formed when human transform knowledge into wisdom and express or internalize it in his behavior. Through this, a social man is born, and individual knowledge turns into social knowledge, and at an upper level, it change into wisdom and doctrine. To reach this end, some special conditions and measures more special and time-consuming are needed. When a society reached the wisdom stage, it is prosperous and flourished in all goodness and well-beings. In such a society, healthy people in the community are hopeful about future and are able to identify cumulative forces; they will be believed that all people in the community including themselves benefit from these forces and social development [29]. To achieve self-actualization, we also require some sub-components and abilities to have: individuals trying to reach the sublime level of knowledge, promoted individuals capable to understanding the wisdom, individuals empowered in deep understanding, tolerant to pain and able to control emotions, being positive inherently, being afraid of God, and having human morality. Finally, it seems that social health is a general component which has different dimensions. Each of these dimensions is composed of some sub- 
components that could be emerged diversely in various people in human society. Each individual in the society could gain these features based on personal capability and effort to promote and extend them. For human beings in the society, it is highly crucial to try to achieve these features. In other words, reaching social health demands universal, comprehensive effort from all community members. One example of the main classes (as a result of categories or sub-categories) along with its concepts or ingredients is shown in Figure 3.

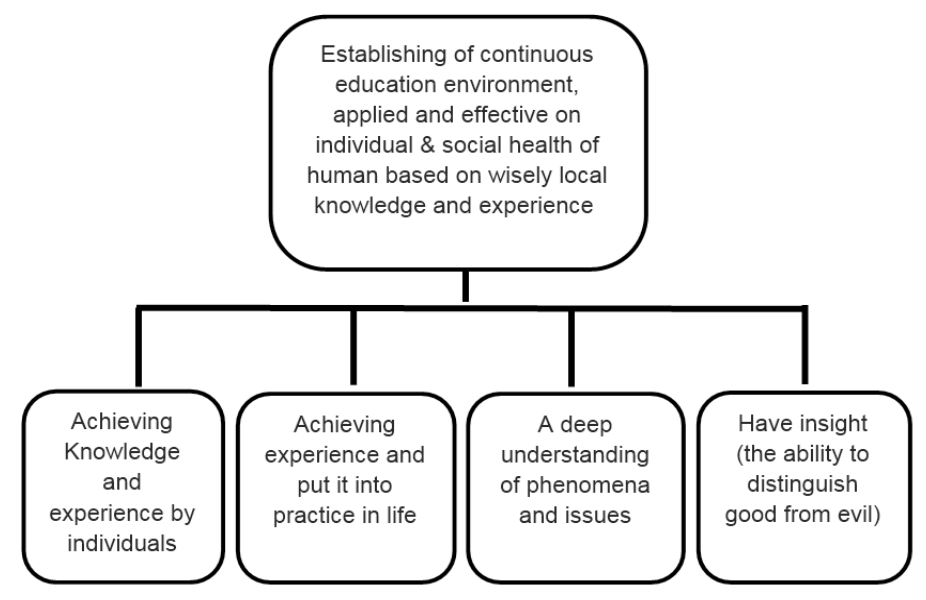

Figure 3 The concepts of main class-forming to create an environment and context of sustainability education, applied and effective on individual \& social health of human based on wisely local knowledge and experience

\section{Discussion}

Since wisdom and being wise and its impact on individual and social health of the human is a complex, abstract issue and a detailed, concrete answer to it, in the same way, seems more abstract and difficult, different comments have been proposed by different researchers on the subject, of course, not much deep that somehow it is in accordance with our study results. Some reflection on it has been proposed with sensitivity, and then we also have considered it with sensitivity.

In this qualitative study with Grounded theory approach, most of the participants expressed the necessary components for a man to be wise and have a healthy social life include being knowledgeable, having knowledge, and combining it in application with experience (approximately in point of view of 38\% of the participants) as well as having insight that is the same stage with pure wisdom (flourishing), and the man reaches the stage of deep understanding of issues and why. These concepts (sub-components) are important and are consistent with religious teachings and sayings of the great religion men for a healthy life and social health both physically and mentally [24-26]. It seems that wisdom is in accordance with the issue of morality that is of religious teachings and extracts, and confirms it. Wisdom has a strong, positive impact on human health and satisfaction in our lives, and can be one of the 5-fold dimensions of Keyes to form social-actualization. To solve the problems and crises confronting humanity today, technology, knowledge and techniques available can be of necessity conditions, but not the sufficient condition. Meeting global challenges in the shadow of transforming knowledge into wisdom and its internalization in humans is possible through reading and studying books with a predetermined aim to meet wisdom. It seems that having a book-reading and studying habit and reading culture and applying the results of knowledge in today current life and making a life based on knowledge and wisdom is the only way to save mankind from the conflicts and challenges he is faced with and the only way to individual and social health. Only with the help of wisdom people can take adequate 
advantage of their life, reach the goal, and cultivate humans as they are faithful and moral to provide a utopian Islamic society (social acceptance); these results are in accordance with those of Khosravi, Riahi and Maxwell $[1-2,4]$. Knowledge is transformed into practice and internalized in the wise man and is also manifested in his behavior and shows its impact. Wisdom is stored knowledge and experience gathered in a learning organization from the participants' point of view, and leads to needed vision for the future (social actualization). It is capable to Judge between good and evil (9.43\% of the participants), and has the ability of problem-solving. The results of our study with the above statements such as applying knowledge, philosophy of knowledge and loving it, capability and ability to solve problems and vision or judgment between good and evil (social acceptance), that are characteristic of wisdom and intellectuality and a wise man, are consistent with the research results by researchers such as Maxwell, Hemmati and are corresponded to our religious teachings [5,23-26].

If people adjust their lives to assess and correct thinking, storm of difficulties and troubles will never destroy them and their life, but can make them strong and resistant against life unpleasant events with relying on their appreciation and use of current facilities to both bring their talent to flourish and to check the convenient way out of the problems and guarantee their overall health. Useful life can be achieved in the shadow of wisdom, which is the application of knowledge; it can provide convenience, comfort, security, prosperity, and happiness in both worlds and can increase the overall social health and satisfaction in his life. In this case, we can name Keyes compliance and social prosperity that individual can adapt to and be in line with the community that is of dimensions of social health. However, as is evident from the results, the most extracted concepts were related to four categories including knowledge, experience, deep understanding, and insight or the ability to distinguish between good and evil, or wisdom and judgment stage. After analysis of data collected from the participants and the concepts resulted from data which formed the sub-categories, main classes emerged. Then, it seems that by creating a dynamic educational and research environment and rational, proper management and use of knowledge and experience together, it is possible to have a wise healthy lifestyle. as well as, practical training based on local experiences related to the establishment and making a dynamic, logic and social joyful by employing the experiences of sage elites and experts, it is possible to transform and move humans from bottom of the pyramid of knowledge and information to the higher level of wisdom to understand doctrine and be able to put knowledge into practice with cooperation, solidarity, and participation, which is one of the other 5-fold dimensions of Keyes social health, and in this way flourish social actualization up to when they can understand the fruit of knowledge tree, i.e. wisdom. The results of some studies suggest that wisdom is interconnected with and directly related to health, particularly in elderly men is significantly related to health. It leads to have a positive attitude and feeling good about himself and his past life through social acceptance, so we can say that wisdom and intellectuality have strong positive impact on social acceptance that is another dimension of social health [13].

\section{Conclusion}

Based on the obtained results and findings, wisdom, and being wise, even though is an abstract and intangible issue, but equally can play a role in healthy and lively social life and it can setup sub-components and main structures of social health. The most of the participants expressed wisdom as a result of knowledge and experience, deep understanding, and insight; mostly a kind of knowledge that is practical to have positive, comprehensive impact on people's life and to be internalized in the behaviors. In the view point of participants, a society that only knows about the significance of knowledge without 
any aim to put it into practice and proper usage, will not be successful and only will store more knowledge to be thicker. Such a thick body will lead to variety of physical and mental ailments and will be slow in the development and growth. Such a society will not achieve any social health dimensions proposed by Keyes or will not be able to fulfill, shape, and build the components of social health for a wise healthy social life.

To achieve the social health and its 5 dimensions stated by Keyes including social cohesion, social acceptance, social adaptation, social participation and social prosperity or actualization, we require sub-components and structures based on wisdom resulted from knowledge to be able to build and shape them by necessary methods and strategies under current circumstances of the society.

It was understood from the main classes of the table resulted from basic concepts and categories that knowledge management, education, research, training and reforming structures and looking at the local culture and benefiting from it, and empowering people to have a happy, healthy, and energetic life are of necessities of the community; achieving wisdom and being wise requires a long way concerning great efforts and tries at all levels especially from academics.

To achieve social health and each of dimensions, we need a real understanding of society necessities and realizing its positive role and avoiding loss of resources in parallel organizations and institutions; to this end, the government must support and govern any society by providing necessary conditions and spaces such as security and freedom of the press to expand constructive ideas; and also by making opinions and criticism schools to thoughts be expressed openly in a constructive democratic society. Therefore, based on the results obtained, some proposes are expressed to help transform knowledge into wisdom for more impacts on social comprehensive health. In this way, logical education, correct and proper teaching based on native culture and practices are of much importance; this way also is incredibly costeffective and has less complication than some new methods and modern technologies; it also can result from the local and native culture of Iranian and Islamic history. Other proposes based on research findings are as follows:

- Recognize healthy life for ourselves and others and be diligent in achieving health and bring it from potentiality into practice.

- Believe that healthy living and healthy aging is of importance and can be achieved through knowledge and wisdom.

- Extent knowledge as far as we need and be able to put it into action.

- Get the best use of knowledge and wisdom in practice and make it influential on the various aspects of our life.

- Before acquiring specific knowledge, have certain questions, what we are exactly looking for, why we need the knowledge and how we can make it work. During acquiring knowledge be aware that how and to what extent our questions are answered.

- Understand fundamental knowledge principles as far as we can. One way is to find the reflex of the principles on the other fields. For example, find an understanding of the economy aspects in gardening; find symmetrical mathematical principles in psychology and thus change our distinct knowledge into a continuous network. - Avoid memorization of knowledge and try to put it into practice and deep understanding as far as we can.

- Seek and grasp knowledge as far as possible, not waiting for someone else to transfer it to us.

- Think upon our knowledge and spend time for finding and reforming wrongful practices emerged by knowledge. One of the first outcomes of knowledge without wisdom is to be pride [30].

- Believe that wisdom is the highest stage of recognition and epistemology, therefore, strive to achieve the necessary wisdom and understanding to build a society based on wisdom and being wise and provide a wide, comprehensive health for everyone.

- Since the inherent dignity of the human is formed by wisdom, it means that human beings have the ability to be wise [31]. To 
promote dignity, physical and mental health of the human, you should try to promote the culture of wisdom and being wise based on our native knowledge and experience.

- Manage and reform education and research efforts on the basis of a higher purpose of humanity; reform education and culture to train and raise healthy human and healthy society based on necessity knowledge and experience.

- Take care of reforming structures and implementing new technologies, consider their positive and negative impact and try to aware others of them.

- Survey on barriers to wisdom and being wise and consider methods for solving problems and challenges confronting with.

- Make you and others believed that a healthy, happy life is the right of every human and the society he lives in; and be determined to provide it in this way.

\section{Acknowledgments}

Authors praise and thanks deputy research of Islamic Azad University, Science and Research Branch of Tehran and all the participants that cooperated with us.

\section{Contribution}

Study design: ARA, NH, FB

Data collection and analysis: ARA, $\mathrm{NH}$

Manuscript preparation: ARA, NH, FB

\section{Conflict of Interest}

"The authors declare that they have no competing interests."

\section{Funding}

This study was sopported by the Research Deputy of Islamic Azad University, Science and Research Branch of Tehran.

\section{References}

1- Khosravi A, Mousavi SK. Intelectuality and religion, the base of Iranian identity in Shahnameh. Kavoshnameh2008; 16: 99-128.

2- Riahi MA. Ferdousi book. Tehran: Tarhe-No; 2002.

3- UNESCO. Secretary general of the Iranian national commission for UNESCO. Meeting with directors of UNESCO's Science Park to function. September 2,
2013. Iran; Tehran.

4- Maxwell N. Can the world learn Wisdom? Philosophy Now2015; 108: 32-5

5- Mehdipour M. Rationality in Ahlebeit culture. Farhang-e-Kowsar2008; 75: 2-7.

6- Tracy B. Crisis management. Mohammadi F, Translator. Qom: Ashkezar; 2016.

7- Bahrani-Esfahani ABN. Avalemalolum va almaaref val ahval menalayat valakhbar val aghval: felahval alemam alhojjat ibn alhasan almahdi (pbuh). Qom: Atre-Etrat; 2011. pp: 29.

8- Soleimani F. The relationship between science and faith from perspective of Molla Mohsen Feiz Kashani. Rahnamoon2008; 24: 171-200.

9- Mesbahi A. The necessity of wisdom and rationality (Part III). 2013; [1 screen]. Available atURL: http://amesbahi.andishvaran.ir/fa/ShowNote. html?ItemId=3601. Accessed Aug 27, 2016.

10- The Holy Quran. Surah Al-Baqarah: verse of 164, Surah Ar-Rum: verse 24, Surah Al-Nahl: verse 12. Saffarzadeh T, Translator. Qom: Osveh; 2016.

11- The Holy Quran. Surah Al-Mulk: verse 10. Saffarzadeh T, Translator. Qom: Osveh; 2016.

12- Johnson S. Wit and wisdom of Samuel Johnson. London: Oxford, Clarendon press; 1888.

13- Ardelt M. Wisdom and life satisfaction in old age. J Gerontol B Psychol Sci Soc Sci1997; 52(1): 15-27.

14- Eliot TS. Where is the wisdom we have lost in knowledge? 2012; [1 screen]. Available atURL: http:// www.foundationsmag.com/wisdom.html. Accessed Aug 27, 2016.

15- Hedayati M, Shomali MA. A query in theoretical and applied wisdom. Marefat-e-Falsefi2009; 6(3): 213-62.

16- Amini Rarani M, Mousavi MT, Rafiey H. Correlation of Social Capital with Social Health in Iran. Social Welfare2011; 11 (42): 203-28.

17- Fathi M, Ajamnezhad R, Khakrangin M. The factors related with teachers' social health in Maragheh City. Social Welfare2012; 12(47): 225-43.

18- Corbin J, Straus A. Basics of qualitative research: Techniques and procedures for developing grounded theory. 3rd ed. Los Angeles, CA: Sage; 2008.

19- Ackoff RL. From data to wisdom. Journal of Applies Systems Analysis 1989; 16: 3-9.

20- Ajam H, Atarodi A, Azghandi M, Shareenia M, Shojaee H. Information technology and computer application for medical students. Tehran: AndishehRafie; 2014.

21- Zeleny M. Management support systems: Towards Integrated Knowledge Management. Hum Syst Manag1987; 7(1): 59-70.

22- The Holy Quran. Ash-Shura Surah: verse 69-74, Az-Zukhruf Surah: verse 22-24. Qom: Osveh; 2016. 
23- Ebne babooye MA. Oyun-Akhbar-Alreza. Banpour A, Translator. Mashhad: Ostvar; 2013.

24- Horre-Amoli MBH. Wasa'il al-Shi'a. Qom: Tebyan; 2009.

25- Hakimi MR, Hakimi M, Hakimi A. Al-Hayat. Aram

A, Translator. 1st ed. Qom: Dalile-Ma; 2012.

26- Koleini SE. Usul Al-Kafi. Komrehei MB, Translator. Qom: Osveh; 2016.

27- Shobeh-Harani HE. Tohafol-Oghool. Hassanzadeh S, Translator. Qom: Ale-Ali; 2003.

28- Brim OG, Ryff CD, Kessler RC. Chapter twelve. Social well-being in the United States: A descriptive epidemiology. In: Keyes CLM , Shapiro AD, eds. How Healthy Are We? A national study of well-being at midlife. Chicago, IL: University of Chicago press; 2004. pp: 350-72.

29- Salehi S, Sarvari-Majd A. The role of munificence components in human maturity from Imam Reza perspective. Journal of Razavi Culture2016; 4(13): 93120.

30- The critical thinking organization community. A brief history of the idea of critical thinking. 1997; [1 screen]. Available atURL: http://www.criticalthinking.org/pages/ a-brief-history-of-the-idea-of-critical-thinking/408. Accessed Aug 27, 2016.

31- Mohammadpour-Dehkordi S, Akbarian R, Avani Sh. The proportion between rationality and human dignity in Kant and Mulla Sadra's philosophy. MarefateFalsafi2009; 6(4): 11-36. 